\title{
Expression of ErbB receptors during pancreatic islet development and regrowth
}

\author{
M R Kritzik ${ }^{1}$, T Krahl' ${ }^{1}$, A Good ${ }^{1}$, D Gu ${ }^{1}$, C Lai $^{2}$, H Fox ${ }^{2}$ and \\ N Sarvetnick ${ }^{1}$ \\ ${ }^{1}$ Department of Immunology, The Scripps Research Institute, 10550 North Torrey Pines Road, La Jolla, California 92037, USA \\ ${ }^{2}$ Department of Neuropharmacology, The Scripps Research Institute, La Jolla, California 92037, USA \\ (Requests for offprints should be addressed to N Sarvetnick; Email: noras@scripps.edu) \\ (D Gu is now at Selective Genetics, La Jolla, California 92037, USA)
}

\begin{abstract}
We have characterized expression of the ErbB receptor family and one of its ligands, heregulin, in an effort to identify molecules associated with pancreatic development and regeneration. In addition to studying expression during fetal pancreatic development, we have also studied expression during pancreatic regeneration in the interferon-gamma (IFN $\gamma$ )-transgenic mouse, which exhibits significant duct cell proliferation and new islet formation. These studies demonstrate significant expression of the ErbB2, ErbB3, and ErbB4 receptors, in addition to heregulin isoforms, in the developing murine fetal pancreas. We also report significant ductal expression
\end{abstract}

of these proteins during IFN $\gamma$-mediated pancreatic regeneration. This striking expression was absent in 1-week-old neonates, but was clearly visible in pups by 5 weeks of age. These data therefore indicate that ErbB receptor and ligand expression decline by birth in both the IFN $\beta$ transgenic and non-transgenic mice, and that expression resumes early in postnatal life in the IFN $\beta$-transgenic mice. The expression of ErbB receptor family members at sites of islet development and regrowth suggests that these molecules might be relevant to these processes.

Journal of Endocrinology (2000) 165, 67-77

\section{Introduction}

Type I autoimmune diabetes results from the destruction of insulin-producing $\beta$ cells in the pancreatic islets of Langerhans. Because the pancreas has only very limited regrowth potential, these islets are not replaced after they are destroyed and survival depends on the exogenous administration of insulin. We are interested in understanding factors contributing to and enhancing the regrowth potential of pancreatic islets. Our studies have utilized a transgenic mouse in which islet-driven expression of interferon-gamma (IFN $\gamma)$ results in significant pancreatic duct cell proliferation and islet regrowth (Gu \& Sarvetnick 1993, Gu et al. 1994). We have focused our recent efforts on identifying molecules that are expressed in areas of IFN $\gamma$-mediated regeneration, and which might be involved in this remarkable regrowth.

The ErbB receptor family includes ErbB1/HER1 (the epidermal growth factor (EGF) receptor), ErbB2/HER-2/ neu, ErbB3/HER3 and ErbB4/HER4. These receptor protein tyrosine kinases, which regulate the activity of different transcription factors via distinct signaling pathways, are critically involved in development and differentiation. Indeed, receptor-deficient mice display significant developmental abnormalities, exhibiting striking defects in cardiac and neural development (Lee et al. 1995, Gassmann et al. 1995, Erickson et al. 1997, Britsch et al. 1998, Reithmacher et al. 1997). The ErbB2- and ErbB4deficient mice die during mid-embryogenesis (Lee et al. 1995, Gassmann et al. 1995, Erickson et al. 1997, Britsch et al. 1998). ErbB3-deficient mice survive the longest (most die by day E13.5, although some ErbB3-deficient embryos do develop to term) and are viable through organogenesis (Erickson et al. 1997, Reithmacher et al. 1997, Britsch et al. 1998). At this point, additional defects in other organs, such as the pancreas and stomach, are apparent (Erickson et al. 1997). The phenotype of ErbB1 knockout mice varies with the strain used: whereas peri-implantation death is apparent in association with a CF-1 genetic background, embryos with the 129/Sv genetic background die at mid-gestation. In contrast, with a CD-1 background, mutants can live up to 3 weeks after birth. No defects in pancreatic development are apparent in these mice (Sibilia \& Wagner 1995, Threadgill et al. 1995).

The ErbB receptor ligands represent a complex variety of molecules. The EGF receptor binds at least six known ligands, including EGF, transforming growth factor- $\alpha$, 
heparin-binding EGF-like growth factor, amphiregulin, epiregulin and betacellulin (Burden \& Yarden 1997). Other members of the ErbB receptor family appear to function primarily through interaction with the neuregulins, which represent a family of EGF-like growth factors encoded by at least four different genes: NRG1 (previously known as NDF, heregulin, GGF, ARIA, or SMDF), NRG2, NRG3 and NRG4 (Burden \& Yarden 1997, Zhang et al. 1997, Harari et al. 1999). Alternative splicing of transcripts arising from the NRG1 and NRG2 genes results in the production of multiple neuregulin isoforms. Neuregulins induce the growth and differentiation of epithelial, glial, neuronal, and muscle cells, and they modulate cellular responses by activating ErbB family members (Meyer \& Birchmeier 1994). Indeed, distinct isoforms can elicit distinct biological activities, depending on the cellular context, thereby modulating growth and development independently (Meyer et al. 1997). Not surprisingly, critical roles for these molecules during development have also been demonstrated. For example, mice lacking heregulins display severe developmental defects and die during embryogenesis. These mice display defects in cardiac and neural development, similar to those seen in ErbB2- and ErbB4-deficient mice (Erickson et al. 1997, Britsch et al. 1998, Meyer \& Birchmeier 1995).

Our interest in the ErbB receptor family stems from several striking observations. Recently, Erickson et al. (1997) have demonstrated that pancreatic development is impaired in ErbB3-deficient mice. In addition, LeBras et al. (1998) have demonstrated that ErbB2 is enriched in the rat embryonic pancreas, as compared with other tissues. Furthermore, Press et al. (1990) have characterized and compared the expression of ErbB2 in human adult and fetal tissue. This group found that ErbB2 was not significantly expressed in the adult pancreas, although weak expression was detected in pancreatic ducts; in contrast, ducts in the fetal pancreas were characterized by more substantial expression of ErbB2. Sundaresan et al. (1998) have also reported ErbB receptor and ligand expression in a ductal epithelial cell line derived from 12-day-old rat embryos. These observations are intriguing: as pancreatic duct cells give rise to endocrine cells during ontogeny, they suggest that expression of ErbB receptors might be important during fetal pancreatic development also. Importantly, the development of endocrine cells from duct cells is mirrored in the IFN $\gamma$-transgenic mouse model of pancreatic regeneration, in which new islet cells are formed continuously from duct cells throughout the life of the animal (Gu \& Sarvetnick 1993, Gu et al. 1994). In this report, we describe ErbB receptor and ligand expression in the regenerating pancreas of the IFN $\gamma$-transgenic mouse, and in the fetal pancreatic ducts during development. Our results suggest that ErbB receptor family members might be involved in pancreatic islet development and regrowth.

\section{Materials and Methods}

\section{Animal husbandry}

Animals were maintained in a specific pathogen-free facility at The Scripps Research Institute according to the rules and regulations governed and enforced by the Institutional Animal Care and Use Committee. Animals were housed under a controlled 12-h light : 12-h darkness cycle; food and water were available ad libitum.

\section{Transgenic mice}

Transgenic mice expressing IFN $\gamma$ have been described previously $(\mathrm{Gu}$ \& Sarvetnick 1993, Gu et al. 1994, Sarvetnick et al. 1988). The IFN $\gamma$-transgenic mice used in these studies were of the non-obese diabetic (NOD) genetic line. Duct cell expansion and new islet growth similar to that seen in Balb/c mice are also observed in IFN $\gamma$-transgenic mice having a NOD genetic background. In addition, IFN $\gamma$-transgenic mice that have been backcrossed onto the NOD/Shi strain for more than 10 generations have a very low incidence of diabetes - less than $20 \%$ compared with NOD mice, which exhibit an incidence of $\sim 25 \%$ for males and $\sim 80 \%$ for females. Embryos were harvested at defined stages of development, with the day of plug formation counted as day E0.5.

\section{Immunohistochemistry}

Pancreata harvested from mice were fixed overnight in $10 \%$ neutral buffered formalin (3.6\% formaldehyde) and embedded in paraffin. Paraffin sections $5 \mu \mathrm{m}$ thick were either conventionally stained with hematoxylin and eosin for histological evaluation, or stained with the antibodies described below using immunocytochemical techniques. Briefly, sections were deparaffinized and blocked with 2\% normal goat serum before applying the primary antibodies (Santa Cruz Biotechnology, Santa Cruz, CA, USA: ErbB2 (No. sc-284), ErbB3 (No. sc-285), ErbB4 (No. sc-283), heregulin $\alpha$ (HRG $\alpha$ ) (No. sc-348), HRG $\beta 3$ (No. sc-347); DAKO, Carpinteria, CA, USA: insulin (No. A0564), glucagon (No. A565), somatostatin (No. A566); ICN, Lisle, IL, USA: PPP (No. 64-711-1)). The ErbB receptor and ligand antibodies were raised against peptides (17-20 amino acids in length) specific for each protein. Western blot analyses carried out by the manufacturer on murine samples have demonstrated that the antibodies against ErbB2, ErbB3, and ErbB4 do not crossreact. Distinct patterns of expression are seen with each of these antibodies in immunohistochemistry also, further indicating the specificity of these reagents. In addition, the HRG $\beta 3$ antibody does not crossreact with other heregulin family members. The HRG $\alpha$ antibody is directed against a peptide from the carboxyl terminus of the heregulin 

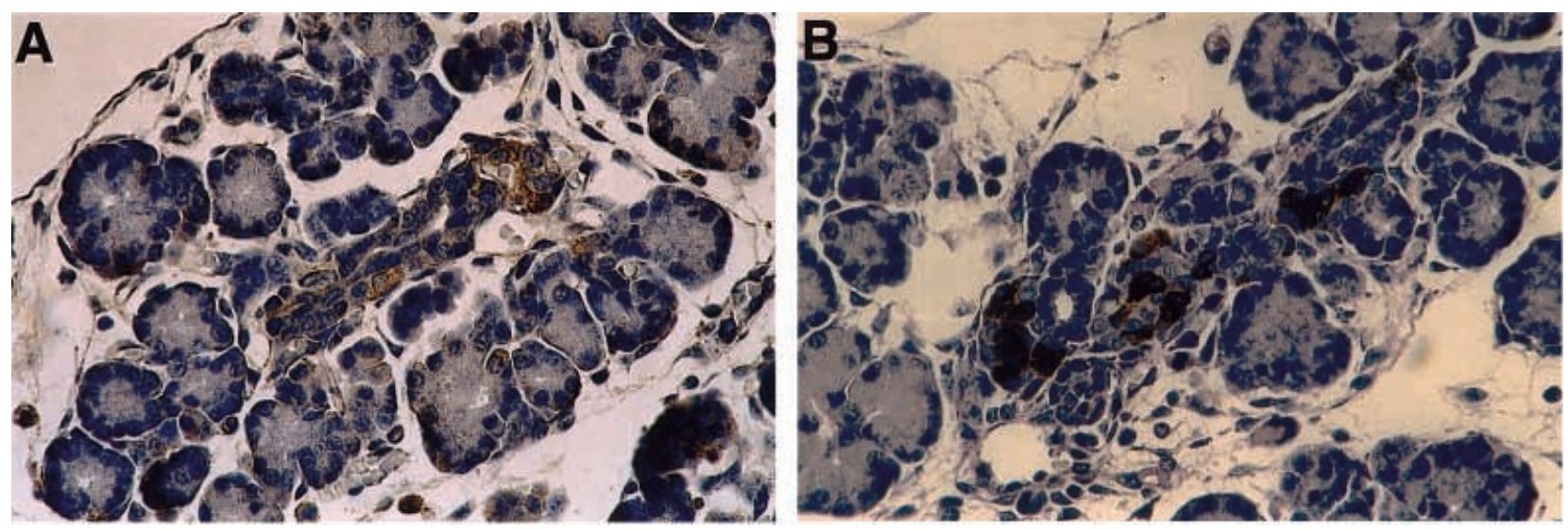

Figure 1 ErbB2 and insulin immunostaining of the fetal pancreas. Pancreatic sections of a day E14.5 Balb/c embryo were immunostained with antibody to either ErbB2 (A) or insulin (B), using the ABC technique (brown is positive staining). Gill's hematoxylin was the counterstain. Note that ErbB2 is expressed in both the ductal and peri-ductal regions, whereas insulin is found mainly in the peri-ductal region. Original magnifications, $\times 50$.
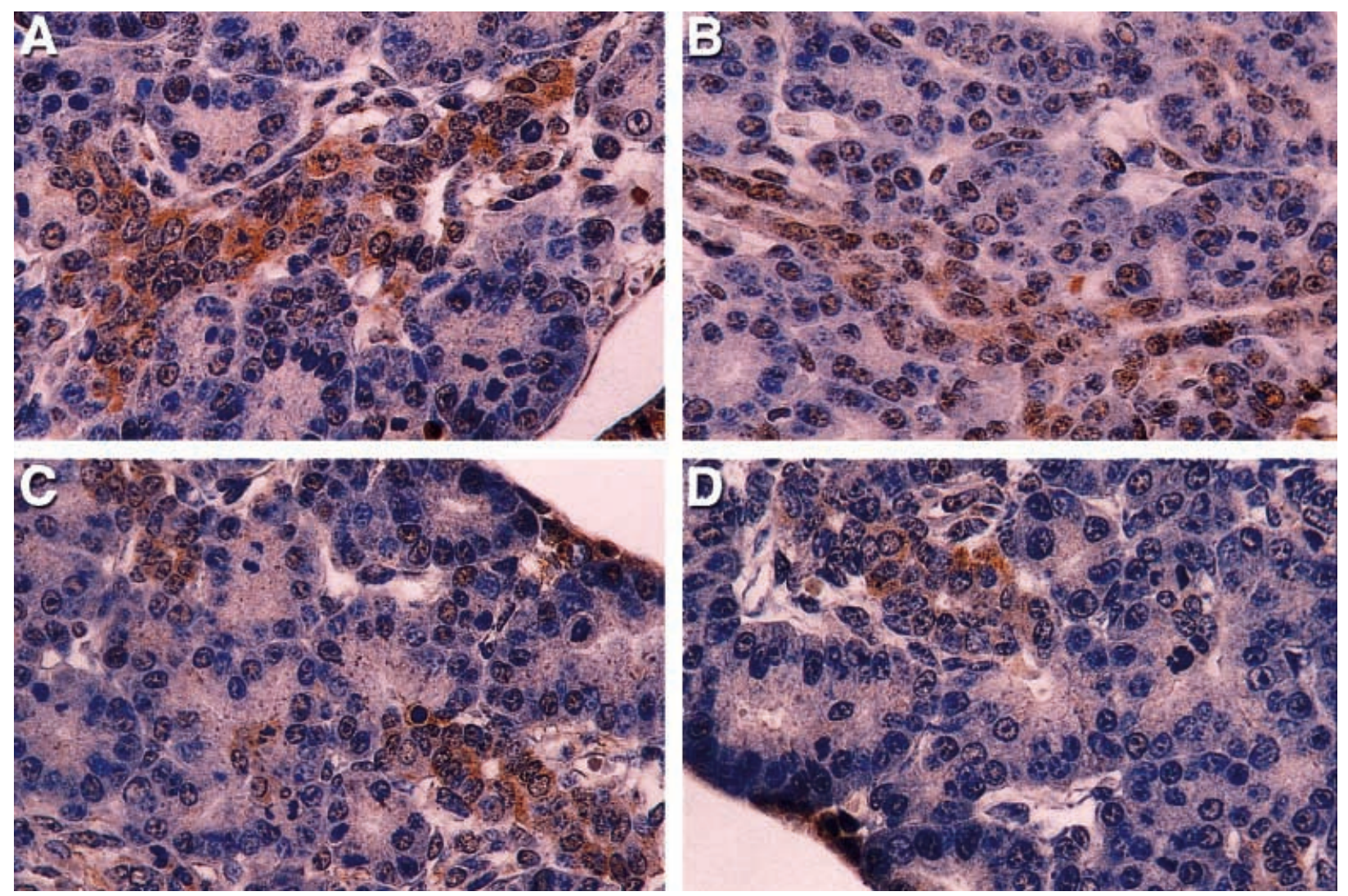

Figure 2 ErbB receptor and ligand immunostaining of the fetal pancreas. Pancreatic sections of a day E16 Balb/c embryo were immunostained with antibody to ErbB3 (A), ErbB4 (B), HRG $\alpha(C)$ or HRG 33 (D), using the ABC technique (brown is positive staining). Gill's hematoxylin was the counterstain. Note the significant expression of ErbB receptors and ligands in the fetal pancreatic ducts. Original magnifications, $\times 40$.

precursor; although it is non-crossreactive with mature forms of the heregulin family and will not recognize HRG $\beta 3$, other $\alpha$ and $\beta$ heregulin isoforms might be detected with this reagent. Binding of the primary antibody was detected using the appropriate secondary antibody (Vector Laboratories, Burlingame, CA, USA), and 

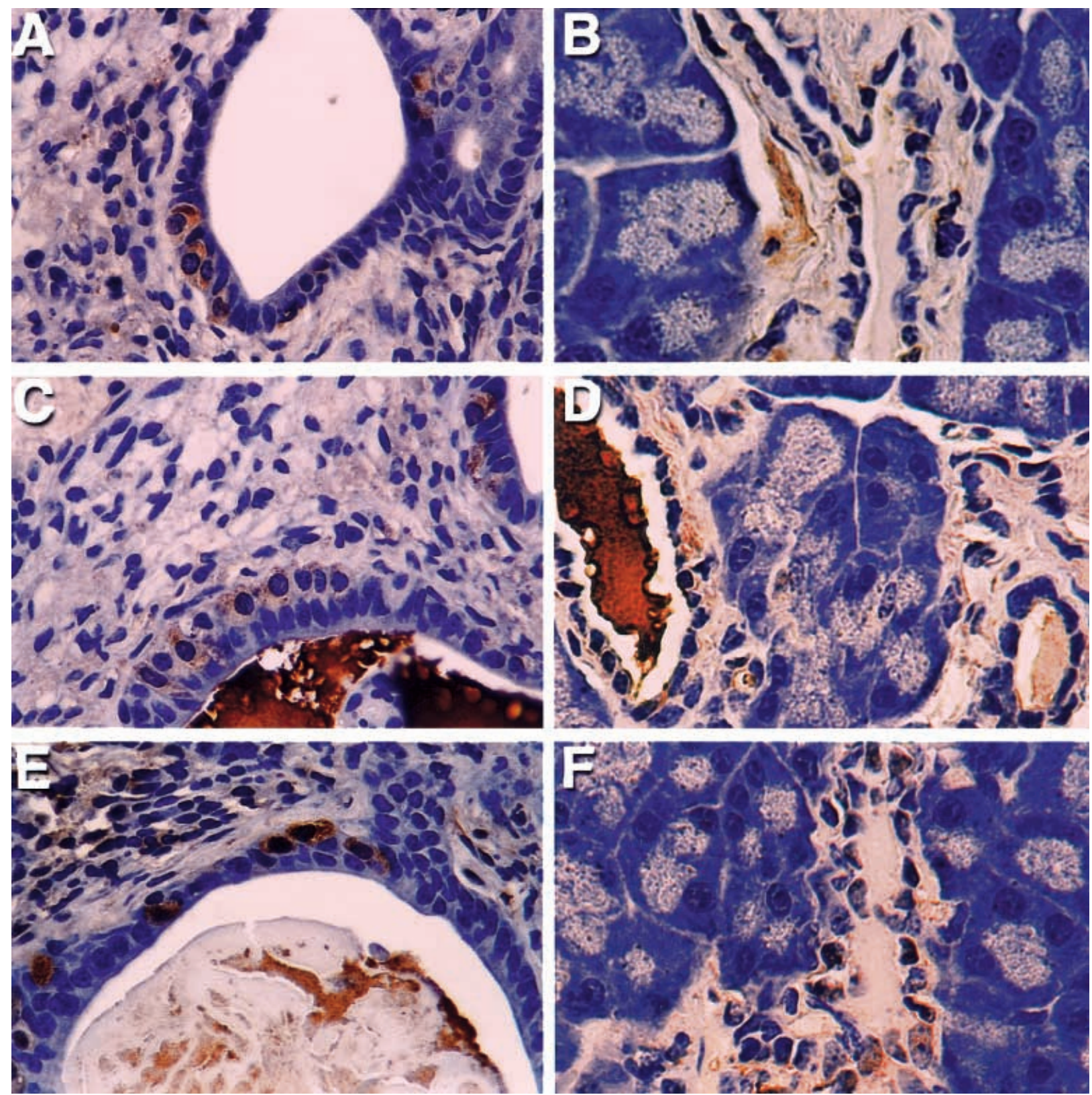

Figure 3 ErbB receptor immunostaining of the IFN $\gamma$-transgenic pancreas. Pancreatic sections from adult IFN $\gamma$-transgenic mice (with the NOD genetic background) (A, C, E) and NOD controls (B, D, F) were immunostained with antibody to ErbB2 (A, B), ErbB3 (C, D) or ErbB4 (E, F), using the $A B C$ technique (brown is positive staining). Gill's hematoxylin was the counterstain. Note the striking expression of ErbB receptors in the pancreatic ducts of IFN $\gamma$-transgenic mice, but not in non-transgenic mice. Original magnifications: $A, B, C, E$, $\mathrm{F}, \times 80 ; \mathrm{D}, \times 64$

the horseradish peroxidase (HRP)-labeled avidin-biotin complex (ABC kit, Vector Laboratories). Endogenous peroxidase activity was quenched with $1 \%$ hydrogen peroxide in methanol. HRP was visualized using $3,3^{\prime}-$ diaminobenzidine as a substrate. Gill's hematoxylin was used as a counterstain.

\section{Results}

ErbB receptor and ligand expression during fetal development To begin to assess the involvement of ErbB receptors during pancreatic development, we first sought to characterize ErbB receptor expression in the fetal pancreas 

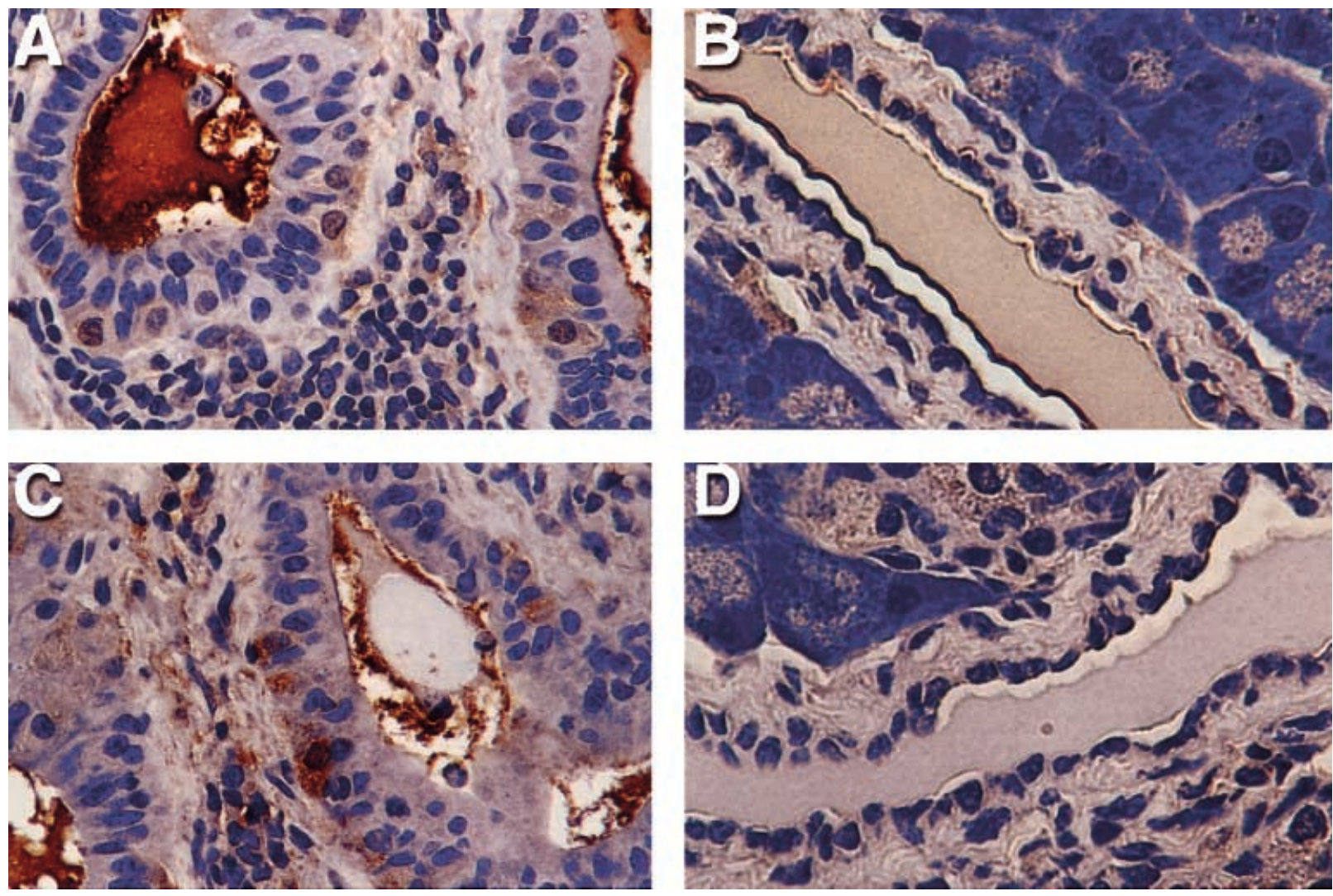

Figure 4 Immunostaining of ErbB receptor ligands in the IFN $\gamma$-transgenic pancreas. Pancreatic sections from adult IFN $\gamma$-transgenic mice (with the NOD genetic background) $(A, C)$ and NOD controls $(B, D)$ were immunostained with antibody to either $H R G \alpha(A, B)$ or HRG $\beta 3$ (C, D), using the $A B C$ technique (brown is positive staining). Gill's hematoxylin was the counterstain. Note the significant expression of ligands in the pancreatic ducts of IFN $\gamma$-transgenic mice, but not in non-transgenic mice. Original magnifications: $\mathrm{A}$, C, $\times 80 ; B, D, \times 64$.

during mouse development. We have previously demonstrated the presence of ErbB1 (the EGF receptor) in the apical cytoplasm of select acini in the IFN $\gamma$-transgenic pancreas (Arnush et al. 1996). These acini appeared to be in a state of transition, as they exhibited ductal characteristics. Most ducts in the transgenic pancreas did not express ErbB1. Therefore, we chose to concentrate our studies on the other members of the ErbB receptor family. To this end, fetal sections taken from non-transgenic mice were analyzed for expression of the ErbB2, ErbB3, and ErbB4 receptors. As indicated in Fig. 1A, we observed significant expression of ErbB2 in the primitive ducts of the fetal pancreas at day E14.5. We also observed some staining in cells within acinar structures. For comparison with ErbB2 receptor staining patterns, Fig. 1B illustrates the pattern of insulin staining in the day E14.5 fetal pancreas. As illustrated in this figure, most of the insulin stain is localized to the periphery of the fetal ducts. As with ErbB2 staining, ErbB3 and ErbB4 were also expressed in the fetal ducts during pancreatic development (Fig. 2A, B).

Given the expression of the ErbB receptors in the fetal pancreas, we anticipated that ErbB receptor ligands would also be present in this region. Because the heregulindeficient mice displayed defects similar to those observed in the ErbB receptor-deficient mice (Meyer \& Birchmeier 1995, Erickson et al. 1997, Britsch et al. 1998), we also assessed expression of heregulin isoforms. These analyses demonstrated significant immunoreactivity with both the HR $G \alpha$ and HR G $\beta 3$ antibodies in the fetal ducts, indicating the presence of heregulin isoforms during fetal pancreatic development (Fig. 2C, D). The demonstration of significant ErbB receptor and ligand expression in the primitive ducts of the fetal pancreas is striking and, given the ductal derivation of endocrine cells during pancreatic development, it suggests that this receptor family might be important for pancreatic islet development during ontogeny.

\section{ErbB receptor expression in pancreatic ducts of the IFN $\gamma$-transgenic pancreas}

Given the expression of ErbB receptor and ligand expression during fetal pancreatic development, we reasoned that ErbB receptor expression might be enhanced during pancreatic islet regeneration also. The IFN $\gamma$-transgenic 

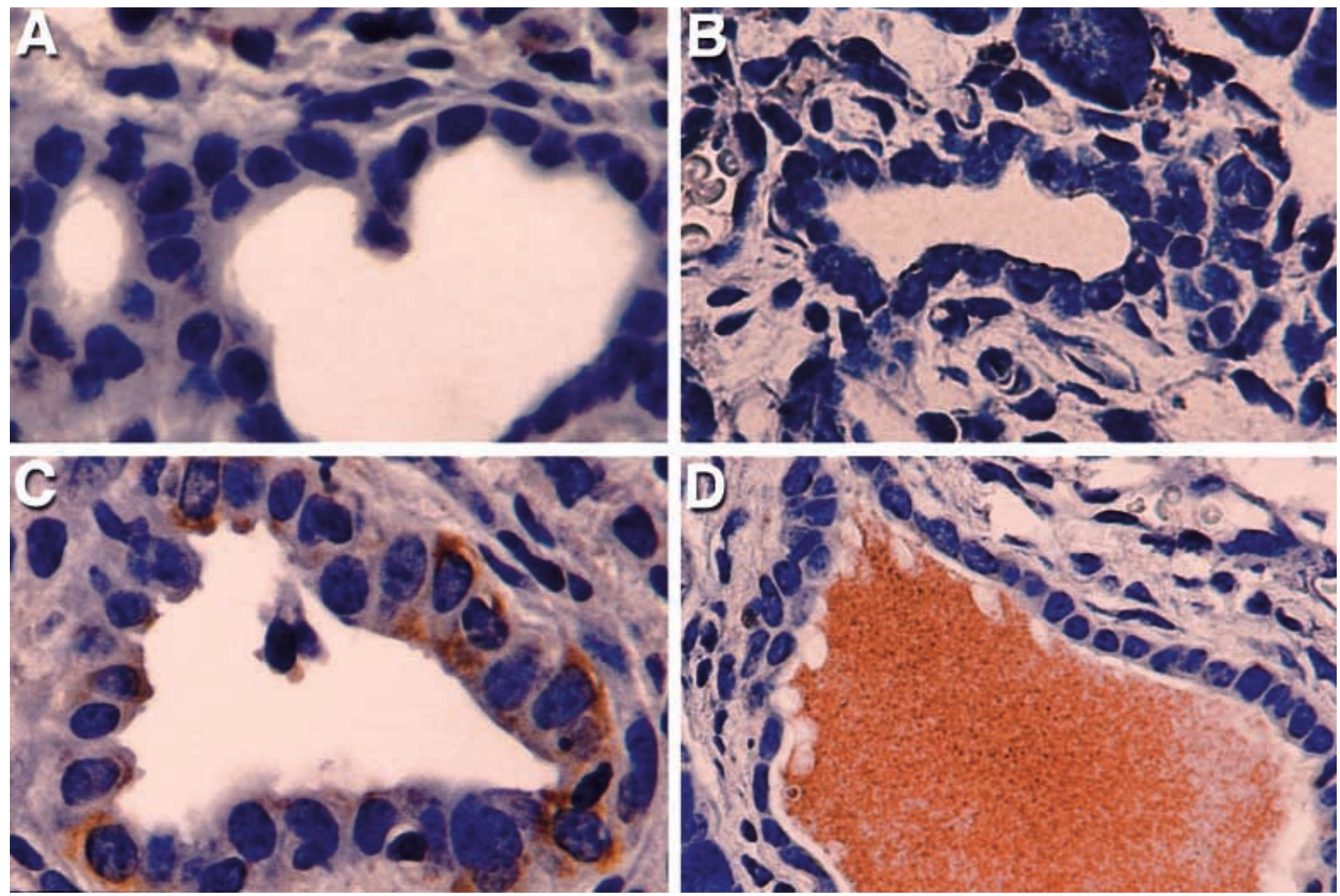

Figure 5 Postnatal expression of ErbB2 in the IFN $\gamma$-transgenic pancreas. Pancreatic sections from 1-week-old (A, B) or 5-week-old (C, D) IFN $\gamma$-transgenic pups (with the NOD genetic background) (A, C) and NOD non-transgenic control pups (B, D) were immunostained with antibody to ErbB2 using the $\mathrm{ABC}$ technique (brown is positive staining). Gill's hematoxylin was the counterstain. Note the absence of ErbB2 ductal staining in the 1-week-old IFN $\gamma$-transgenic pup, and the presence of significant ErbB2 immunoreactivity in the 5-week-old IFN $\gamma$-transgenic pup. Significant ductal expression of ErbB2 was not observed in non-transgenic pups at either age. Original magnifications: A, B, × 80; C, D, $\times 64$.

mouse exhibits significant duct cell proliferation and islet growth (Gu \& Sarvetnick 1993, Gu et al. 1994). Previous studies in our laboratory have shown that new endocrine cells are derived from ductal cells in this transgenic mouse ( $\mathrm{Gu}$ et al. 1994). We therefore used immunohistochemistry to define ErbB receptor expression patterns during regeneration in the pancreatic ducts of the IFN $\gamma$-transgenic mouse.

Figure 3A, C and E illustrates ErbB2, ErbB3, and ErbB4 receptor staining in the IFN $\gamma$-transgenic pancreas, respectively. Significantly, we observed substantial expression of ErbB receptors in duct cells of the regenerating pancreas. The extent and proportion of ErbB receptor-expressing cells varied among ducts, with some ducts containing few, if any, ErbB-positive cells, while other ducts contained many ErbB positive cells. In general, ErbB2 staining was much more widespread than ErbB3 or ErbB4 staining. We also stained the regenerating pancreas for expression of heregulin isoforms. We observed significant duct-cell-specific expression using both the
HRG $\alpha$ and $H R G \beta 3$ antibodies in the transgenic pancreas also (Fig. 4A, C). Although the intense ErbB receptor and ligand expression patterns observed in ducts of the IFN $\gamma$-transgenic pancreas were not observed in the nontransgenic pancreas, we did observe occasional weak ErbB receptor and ligand staining in the ducts of non-transgenic mice (Fig. 3B, D and F; Fig. 4B, D). The acinar tissue did not stain with any of the heregulin ligand or receptor antibodies used.

ErbB receptor and ligand expression in pancreatic ducts during postnatal pancreatic development

The expression of ErbB receptors in both the fetal pancreas and the IFN $\gamma$-transgenic pancreas is in contrast to our observations in the adult non-transgenic pancreas. These findings suggested that either ErbB receptor expression was maintained in the transgenic pancreas from early in development through adulthood, or that it declined as in the non-transgenic fetal pancreas, only to be induced 

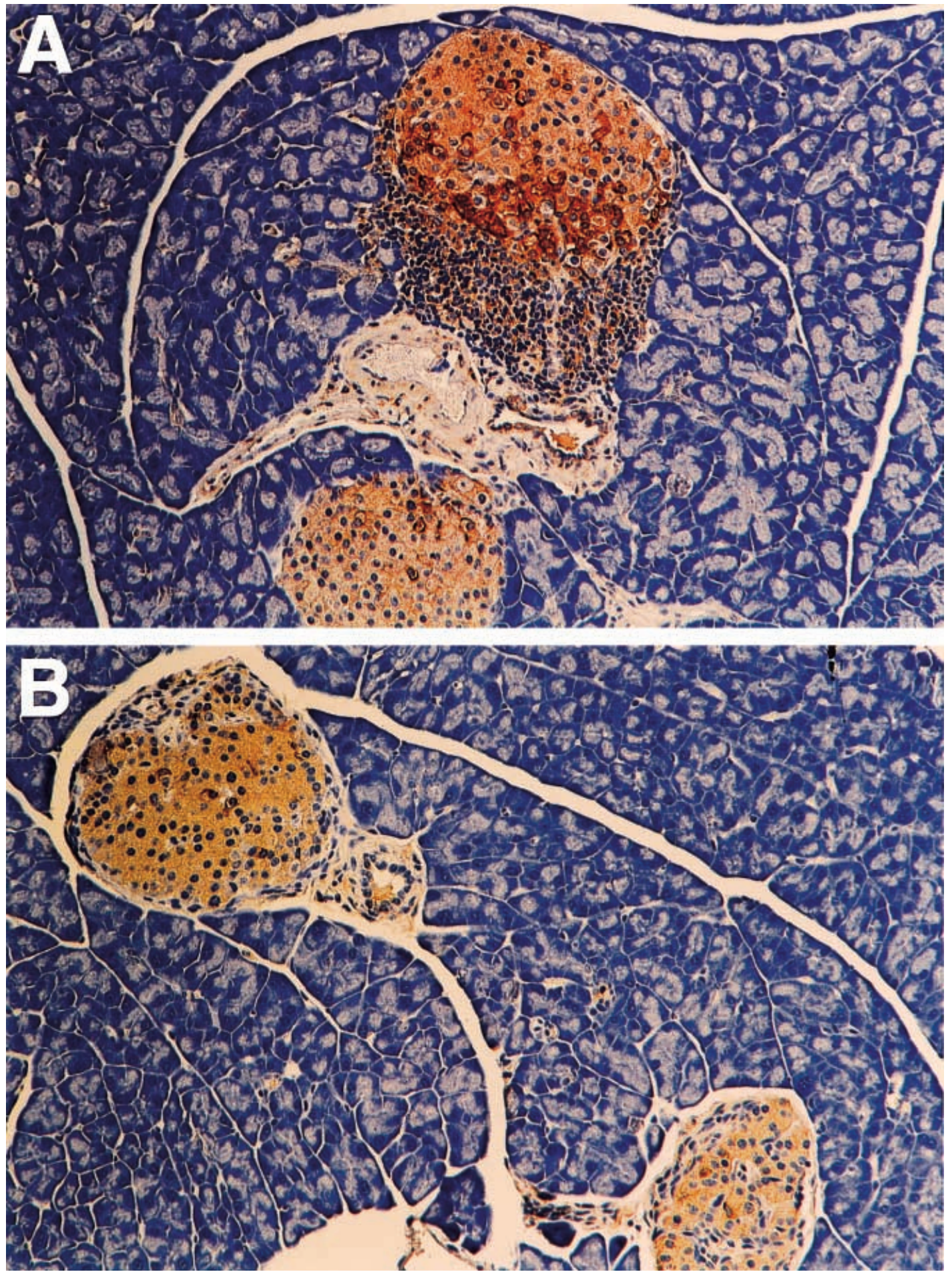

Figure 6 Pancreatic islet expression of ErbB2. Pancreatic sections from NOD (A) and NOD.SCID (B) mice were immunostained with antibody to ErbB2 using the ABC technique (brown is positive staining). Gill's hematoxylin was the counterstain. Note the striking enhancement of ErbB2 expression in infiltrated islets. Original magnifications, $\times 20$. 

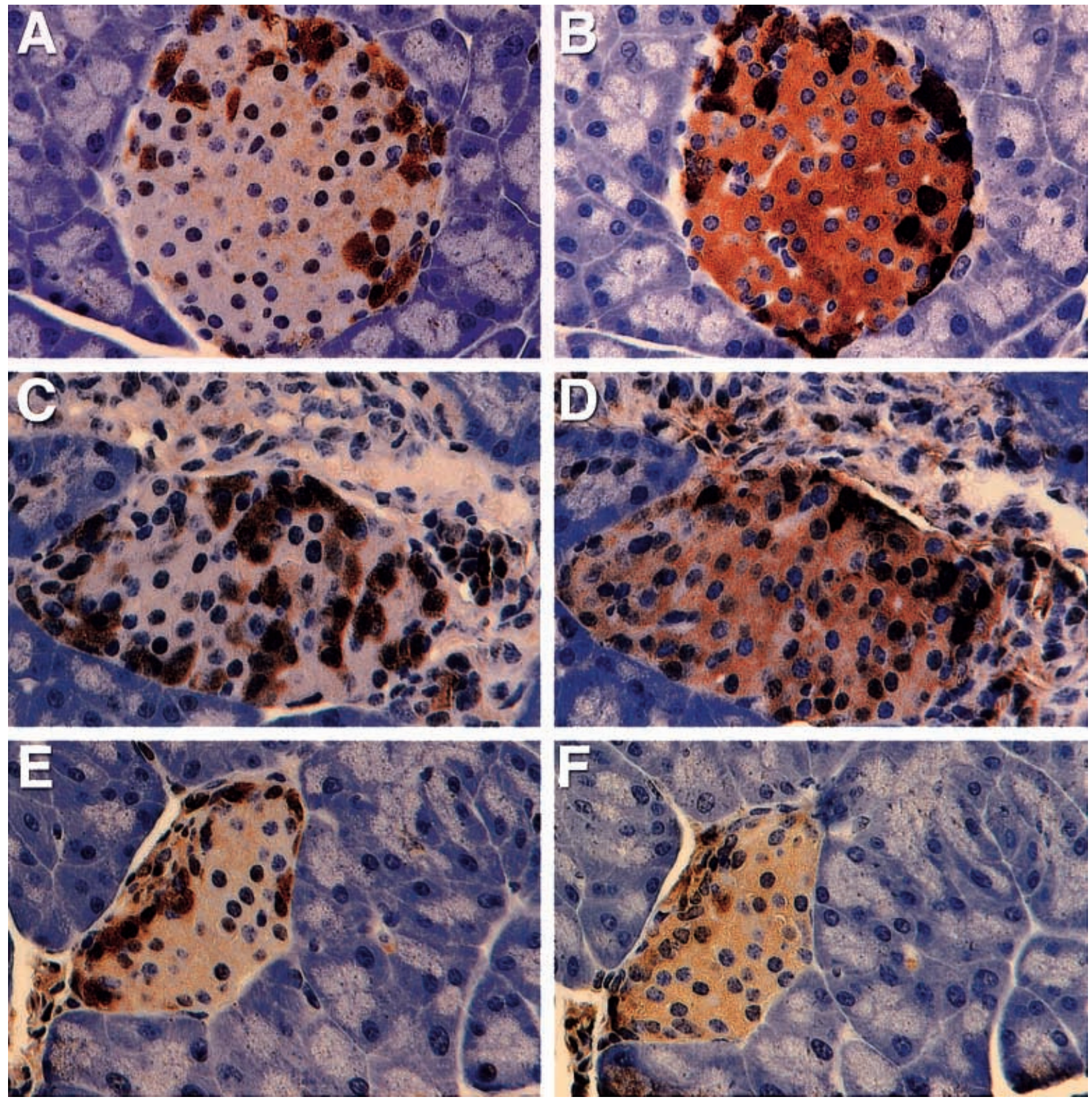

Figure 7 Pancreatic islet expression of ErbB4. Pancreatic sections from NOD mice were immunostained with antibodies to ErbB4 (A, C, $\mathrm{E})$, glucagon (B), somatostatin (D) or pancreatic polypeptide (F), using the $A B C$ technique (brown is positive staining). Gill's hematoxylin was the counterstain. Serial sections were stained (A/B; C/D; E/F). Note the coincident staining patterns seen with the ErbB4 and glucagon antibodies. Original magnifications, $\times 40$.

postnatally. These distinct possibilities prompted us to examine the pattern of ErbB receptor expression in the IFN $\gamma$-transgenic and non-transgenic pancreas early in postnatal life.

We stained pancreatic sections taken from IFN $\gamma$ transgenic and non-transgenic mice soon after birth, at 1 week of age, with the ErbB2, ErbB3, ErbB4, HRGa, and
HRG $\beta 3$ antibodies. Interestingly, we did not detect significant staining in the ducts of the transgenic or non-transgenic mice with any of the antibodies screened (Fig. 5A, B, and data not shown). We next examined expression a few weeks later, at 5 weeks of age, in order to determine if expression had recommenced in the transgenic mice at this point. In mice of this age, we were already able 
to observe some expansion of pancreatic ducts in the transgenic mice compared with the non-transgenic mice. Indeed, by this time, we also observed a number of ducts showing significant staining using the ErbB receptor and ligand antibodies in the IFN $\gamma$-transgenic mice, but not in the non-transgenic mice (Fig. 5C, D, and data not shown). These data indicate that, whereas ErbB receptor and ligand expression decline significantly by birth in both IFN $\gamma$ transgenic and non-transgenic mice, expression resumes in the transgenic mice relatively early in postnatal life.

\section{ErbB receptor expression in pancreatic islets}

We observed a striking induction of intra-islet ErbB2 expression in islets that exhibited infiltration by inflammatory cells, compared with non-infiltrated islets (Fig. 6A); the enhanced ErbB2 islet staining was found to be adjacent to the infiltrates. Within the same field, we observed islets exhibiting different degrees of ErbB2 induction, with the degree of expression correlated with the extent of lymphocytic infiltration of the islet. Indeed, this striking induction of ErbB2 staining was not observed in the absence of islet infiltration, as in NOD.severe combined immunodeficiency (SCID) mice (Fig. 6B). ErbB4 receptor staining also exhibited a distinct pattern of expression: increased ErbB4 expression was predominantly localized at the periphery of the islets, in a pattern reminiscent of glucagon-secreting A cell organization (Fig. 7). Indeed, staining of serial sections with glucagon and ErbB4 demonstrated coincident staining patterns (Fig. 7A, B). This pattern of expression is distinct from somatostatin, pancreatic polypeptide, and insulin staining patterns (Fig. 7C-F, and data not shown). In contrast, islet staining with the ErbB3 antibody did not exhibit such striking patterns of expression.

\section{Discussion}

The ErbB receptor family members are expressed at a wide variety of sites during development, including the fetal pancreas (Press et al. 1990, Prigent et al. 1992). In these studies, we have further examined the expression of this receptor family during fetal pancreatic development, and have observed defined expression of ErbB receptors in the primitive fetal ducts, from which endocrine cells and, hence, new islets develop. In addition, we have explored receptor expression in the IFN $\gamma$-transgenic mouse, which exhibits striking duct cell proliferation and new islet formation throughout adulthood. The expression of ErbB receptor family members during new islet formation in the IFN $\gamma$-transgenic mouse, and in islet development during ontogeny, suggests a role for these molecules in the development and regrowth of pancreatic islets. Indeed, the ductal derivation of endocrine cells during fetal islet development has been well described, and we have previously shown that endocrine cells derive from duct cells in the IFN $\gamma$-transgenic pancreas ( $\mathrm{Gu}$ et al. 1994). These data suggest that endocrine progenitor cells exist within the pancreatic ducts and can initiate new islet growth under the appropriate conditions. Given their expression during islet growth in development (in the fetal pancreas) and regeneration (in the IFN $\gamma$-transgenic pancreas), our data further suggest that the ErbB receptors are associated with endocrine progenitor cells within the duct wall.

Whereas ducts in the IFN $\gamma$-transgenic pancreas exhibited significant expression of the ErbB receptors and the heregulins, those in the non-transgenic NOD pancreas did not. This is in contrast to studies of the fetal pancreas during development. On examination of ErbB receptor and ligand staining patterns during pancreatic development, we observed considerable staining in the fetal ducts of non-transgenic embryos. In addition, we found that ductal expression of these receptors diminishes by 1 week of age. We subsequently noted the resumption of ErbB receptor expression in the pancreatic ducts after a few weeks of life in the IFN $\gamma$-transgenic mice. The specific mechanism by which expression of ErbB receptors and ligands are induced during IFN $\gamma$-mediated pancreatic regeneration is not clear; it is possible that these molecules are induced by the inflammation resulting from $\beta$-cell-directed IFN $\gamma$ expression.

Considerable evidence exists that suggests that the formation of receptor heterodimers between members of the ErbB receptor family has an important role in mediating signaling events (Burden \& Yarden 1997). Indeed, although nearly all receptor combinations are able to form, ErbB2 appears to be the preferred heterodimerization partner for the other ErbB receptors. In addition, receptor complexes with ErbB2 appear to have the greatest affinity for ligand and are the most active complexes. However, none of the ligands described so far appears to bind ErbB2 directly. Rather, a variety of studies have shown that several ligands, including EGF, neuregulins, and betacellulin, are able to mediate the phosphorylation and activation of ErbB2, via heterodimerization with ErbB1, ErbB3, or ErbB4. Importantly, recent work by Sundaresan et al. (1998) has demonstrated that the ability of cells to respond to a given ligand is dependent on the expression of specific ErbB receptor combinations in the target tissue. In addition, Jones et al. (1999) have recently documented the extreme variations in ligand binding specificities and affinities observed with different ErbB receptor dimer combinations. Thus diversity in signaling events involving ErbB receptors is generated by a number of critical factors, including ligand isoforms, receptor dimer composition, and the restricted expression of receptors during development and in adulthood. The expression of ErbB2, ErbB3, and ErbB4 receptors in the IFN $\gamma$-transgenic pancreas suggests that multiple combinations of receptor heterodimers are able to form, enabling interaction with a wide 
range of ligands and generating diversity in signaling events. Our major focus in this study has been to document expression of ErbB receptor family members during islet formation, but we have also studied expression of the heregulins during pancreatic development and regeneration in order to correlate receptor and ligand expression. The detection of heregulin family members at times of ErbB receptor expression suggests that these molecules, which have a high affinity for the ErbB2/3 and ErbB2/4 receptor heterodimers (Jones et al. 1999), are likewise involved in ErbB receptor-mediated events.

We observed mainly membrane-associated and cytoplasmic staining of the ErbB receptors. The ErbB receptors are localized to the membrane and are expected to be detected at this location, but others have reported the detection of these receptors in the cytoplasm also (Prigent et al. 1992, Yamanaka et al. 1993, Graber et al. 1999). In addition, we have observed some expression over the nuclear region in both the fetal and the IFN $\gamma$-transgenic pancreas. This was particularly evident for ErbB3, ErbB4, and HRG $\alpha$ in the acinar and ductal regions of the fetal pancreas. Furthermore, the occasional duct staining we observed in the non-transgenic pancreas with the ErbB2, ErbB3, and ErbB4 antibodies was often over the nuclear region; we did not detect any cytoplasmic or membraneassociated ErbB receptor staining in these samples. The ErbB receptor tyrosine kinases are associated with the plasma membrane, and as such are not expected to be localized in the nucleus. Although the significance of the nuclear staining we observe is not clear, nuclear and perinuclear localization of ErbB receptors have been reported previously (Lemoine et al. 1992, Xie \& Hung 1994, Cohen et al. 1998).

We observed a significant enhancement of ErbB2 expression in islets, which correlated with the extent of lymphocytic infiltration of the islet. This increase in the expression of ErbB2 was striking, as intact islets adjacent to infiltrated islets in the same section did not display such increased expression of ErbB2. The nature and significance of the enhanced islet expression of ErbB2 and how it relates to the islet infiltrates are not clear, although these observations clearly warrant further investigation. It is possible that infiltrating cells, such as $\mathrm{T}$ cells, B cells, or macrophages, supply signals that mediate ErbB2 induction in the islets. This induction might be part of a protective response elicited by the islet in response to the infiltration, its expression being part of an attempt to defer destruction. Indeed, we did not observe this striking pattern in the islets of NOD.SCID mice, indicating a role for T cells, B cells, or both, in the intra-islet increase in ErbB2 receptor expression. Interestingly, ErbB4 also gave a distinct pattern of islet expression. In this case, the predominantly peripherally localized expression of ErbB4 in the pancreatic islets was coincident with glucagon staining, and it suggests that ErbB4 might participate directly in the differentiation or maintenance of this endocrine cell type.
In summary, we have demonstrated significant expression of the ErbB2, ErbB3, and ErbB4 receptor tyrosine kinases, and of heregulin ligands, in the fetal pancreas and in the IFN $\gamma$-transgenic pancreas. The association of these molecules with endocrine cell and islet formation suggests that they might play important parts in mediating new islet growth during pancreatic development, and during IFN $\gamma$-mediated pancreatic regeneration.

\section{Acknowledgements}

We would like to acknowledge Lee Tucker and Brian Yeung for their assistance with the breeding and screening of transgenic and non-transgenic mice. We would also like to thank Joanne Dodge for editorial assistance. This work was supported by grants from NIH (HD29764-06 and DK55230-02) and Cytotherapeutics, Inc. (SFP1091).

\section{References}

Arnush M, Gu D-L, Baugh C, Sawyer SP, Mroczkowski B, Krahl T \& Sarvetnick N 1996 Growth factors in the regenerating pancreas of gamma-interferon transgenic mice. Laboratory Investigation $\mathbf{7 4}$ 985-990.

Britsch S, Li L, Kirchhoff S, Theuring F, Brinkmann V, Birchmeier C \& Riethmacher D 1998 The ErbB2 and ErbB3 receptors and their ligand, neuregulin-1, are essential for development of the sympathetic nervous system. Genes and Development 12 825-1836.

Burden S \& Yarden Y 1997 Neuregulins and their receptors: a versatile signaling module in organogenesis and oncogenesis. Neuron 18 847-855.

Cohen BD, Siegall CB, Bacus S, Foy L, Green JM, Hellstrom I, Hellstrom KE \& Fell HP 1998 Role of epidermal growth factor receptor family members in growth and differentiation of breast carcinoma. Biochemical Society Symposia 63 199-210.

Erickson SL, O'Shea KS, Ghaboosi N, Loverro L, Frantz G, Bauer M, $\mathrm{Lu}$ LH \& Moore MW 1997 ErbB3 is required for normal cerebellar and cardiac development: a comparison with ErbB2- and heregulin-deficient mice. Development 24 4999-5011.

Gassmann M, Casagranda F, Orioli D, Simon H, Lai C, Klein R \& Lemke G 1995 Aberrant neural and cardiac development in mice lacking the ErbB4 neuregulin receptor. Nature 378 390-394.

Graber HU, Friess H, Kaufmann B, Willi D, Zimmerman A, Korc M \& Buchler MW 1999 ErbB4 mRNA expression is decreased in non-metastatic pancreatic cancer. International Journal of Cancer 19 24-27.

Gu D-L \& Sarvetnick N 1993 Epithelial cell proliferation and islet neogenesis in IFN-g transgenic mice. Development 118 33-46.

Gu D-L, Lee M-S, Krahl T \& Sarvetnick N 1994 Transitional cells in the regenerating pancreas. Development 120 1873-1881.

Harari D, Tzahar E, Romano J, Shelly M, Pierce JH, Andrews GC \& Yarden Y 1999 Neuregulin-4: a novel growth factor that acts through the ErbB-4 receptor tyrosine kinase. Oncogene 18 2681-2689.

Jones JT, Akita RW \& Sliwkowski MX 1999 Binding specificities and affinities of egf domains for ErbB receptors. FEBS Letters 447 227-231.

LeBras S, Czernichow P \& Scharfmann R 1998 A search for tyrosine kinase receptors expressed in the rat embryonic pancreas. Diabetologia 41 1474-1481.

Lee KF, Simon H, Chen H, Bates B, Hung MC \& Hauser C 1995 Requirement for neuregulin receptor ErbB2 in neural and cardiac development. Nature 378 394-398. 
Lemoine NR, Lobresco M, Leung H, Barton C, Hughes CM, Prigent SA, Gullick WJ \& Kloppel G 1992 The ErbB-3 gene in human pancreatic cancer. Journal of Pathology 168 269-273.

Meyer D \& Birchmeier C 1994 Distinct isoforms of neuregulin are expressed in mesenchymal and neuronal cells during mouse development. Proceedings of the National Academy of Sciences of the USA 91 1064-1068.

Meyer D \& Birchmeier C 1995 Multiple essential functions of neuregulin in development. Nature 378 386-390.

Meyer D, Yamaii T, Garratt A, Reithmacher-Sonnenberg E, Kane D, Theill LE \& Birchmeier C 1997 Isoform-specific expression and function of neuregulin. Development 124 3575-3586.

Press MF, Cordon-Cardo C \& Slamon DJ 1990 Expression of the HER-2/neu proto-oncogene in normal human adult and fetal tissues. Oncogene 5 953-962.

Prigent SA, Lemoine NR, Hughes CM, Plowman GD, Selden C \& Gullick WJ 1992 Expression of c-erbB-3 protein in normal human adult and fetal tissues. Oncogene 7 1273-1278.

Riethmacher D, Sonnenberg-Riethmacher E, Brinkmann V, Yamaai T, Lewin GR \& Birchmeier C 1997 Severe neuropathies in mice with targeted mutations in the ErbB3 receptor. Nature 389 725-730.

Sarvetnick N, Liggitt D, Pitts SL, Hansen SE \& Stewart TA 1988 Insulin-dependent diabetes mellitus induced in transgenic mice by ectopic expression of class II MHC and interferon-gamma. Cell $\mathbf{5 2}$ 773-782.

Sibilia M \& Wagner EF 1995 Strain-dependent epithelial defects in mice lacking the EGF receptor. Science 269 234-238.
Sundaresan S, Roberts PE, King KL, Sliwkowski MX \& Mathers J 1998 Biological responses to ErbB ligands in nontransformed cell lines correlates with a specific pattern of receptor expression. Endocrinology 139 4756-4764.

Threadgill DW, Dlugosz AA, Hansen LA, Tennenbaum T, Lichti U, Yee D, LaMantia C, Mourton T, Herrup K, Harris RC, Barnard JA, Yuspa SH, Coffey RJ \& Magnuson T 1995 Targeted disruption of mouse EGF receptor: effect of genetic background on mutant phenotype. Science 269 230-234.

Xie Y \& Hung M-C 1994 Nuclear localization of $\mathrm{p} 185^{\text {neu }}$ tyrosine kinase and its association with transcriptional activation. Biochemical and Biophysical Research Communications 203 1589-1598.

Yamanaka Y, Friess H, Kobrin MS, Buchler M, Kunz J, Beger HG \& Korc M 1993 Overexpression of HER2/neu oncogene in human pancreatic carcinoma. Human Pathology 24 1127-1134.

Zhang D, Sliwkowski MX, Mark M, Frantz G, Akita R, Sun Y, Hillan K, Crowley C, Brush J \& Godowski PJ 1997 Neuregulin-3 (NRG3): a novel neural tissue-enriched protein that binds and activates ErbB4. Proceedings of the National Academy of Sciences of the USA $949562-9567$.

Received 6 August 1999

Accepted 9 September 1999 